\title{
Clinical assessment of optic nerve disorders
}

\author{
P Riordan-Eva
}

Table 1 Aetiology of optic nerve disorders

\author{
Abstract \\ Optic nerve disorders range from the \\ manifestations of life-threatening intracranial \\ or systemic disease, to minor congenital \\ anomalies. Careful clinical assessment, which \\ relies upon a thorough evaluation of \\ symptoms as well as signs, is essential for \\ effective and timely investigation and \\ treatment. Examination methods and pitfalls \\ to be avoided are discussed. \\ Eye (2004) 18, 1161-1168. \\ doi:10.1038/sj.eye. 6701575
}

Keywords: diagnosis; optic nerve diseases; signs and symptoms

\section{Introduction}

The optic nerve is subject to a wide range of pathology (Table 1) due to intrinsic, intraorbital, intracranial, or systemic disease, including a number of life- as well as sight- threatening conditions. The pattern of disease in optic neuropathies provides guidance to research into the underlying pathological processes and hopefully methods to allow earlier detection and better visual outcomes.

It remains the responsibility of clinicians to determine appropriate management, avoiding unnecessary investigation or treatment wherever possible but more importantly instigating rapid investigation or treatment when indicated. This relies upon reliable assessment and interpretation of clinical findings.

Rarely can the aetiology of optic neuropathy be made on the basis of a single clinical finding. There is considerable overlap of clinical features between even the relatively common optic neuropathies, from which arises the potential value of neural networks. ${ }^{1,2}$ However, in experienced hands clinical diagnosis is reliable and sufficient to avoid or minimise further investigation. ${ }^{3}$ Recognition of retinal disease or
Congenital anomalies

Glaucoma

Inflammatory (optic neuritis)

Ischaemic

Raised intracranial pressure (papilloedema)

Compression

Nutritional and toxic optic neuropathy

Trauma

Inherited optic neuropathy

Infiltrative (neoplastic or granulomatous)

Optic atrophy secondary to retinal disease

nonorganic visual loss masquerading as optic neuropathy is particularly important.

This article discusses clinical assessment of optic nerve disorders with particular emphasis on the relative merits of various examination techniques and pitfalls to be avoided.

\section{Symptoms}

Diagnosis in ophthalmology usually relies heavily upon examination findings, but the range of abnormalities in optic nerve disorders is limited such that the history is often paramount. Abnormal physical signs may determine the presence of optic nerve dysfunction, but symptoms especially the temporal course of visual loss is the guide to aetiology, which in turn determines the probable natural history and potential response to therapy.

The onset of optic neuropathy is not always clear. Many congenital anomalies and even papilloedema may be identified at routine optometric assessment. Similarly, unilateral visual loss may be recognised only when the fellow eye is covered, for whatever reason. Thus, careful questioning may be required to determine when if ever vision in the affected eye was last known to be normal and the duration of related symptoms such as transient visual obscurations of optic disc swelling.
Department of Ophthalmology King's College Hospital London, UK

Correspondence:

P Riordan-Eva

Department of

Ophthalmology

King's College Hospital Denmark Hill

London SE5 9RS, UK

Tel: + 4402073461524

Fax: + 4402073463738

E-mail: paul.riordan-eva@

kingsch.nhs.uk

Received: 4 September 2003

Accepted: 4 September 2003

Presented at Cambridge Ophthalmological Symposium, 4 September 2003

The author has no proprietary interest and has not received any research funding in connection with this article. 
Clarification of the temporal course of visual loss is critical. Ischaemic optic neuropathy generally has a sudden onset, although in some cases there is progressive visual loss over a period of 2 weeks, with moderate recovery at best thereafter. Inflammatory optic neuropathy tends to have a subacute onset over a number of days, frequently accompanied by periocular pain exacerbated by eye movements. ${ }^{4}$ The almost complete recovery of vision over the next few weeks is sufficiently characteristic of the vast majority of cases of demyelinating optic neuropathy to allow a clinical diagnosis, without the need for confirmatory investigation as long as there are no atypical features. 5,6 Compressive optic neuropathy usually causes gradually progressive visual loss, although particularly vascular lesions may cause abrupt visual decline occasionally followed by some recovery. Nutritional or toxic optic neuropathy results in subacute or chronic symmetrical bilateral visual loss. Visual loss due to congenital anomalies rarely changes, except in optic disc pits complicated by serous macular detachment.

Glaucomatous optic neuropathy is not symptomatic until late in the disease course such that it is usually identified incidentally or by screening. In Leber's hereditary optic neuropathy, visual loss most commonly develops sequentially with 8 weeks delay between involvement of the two eyes and progression of visual loss over 4-6 weeks in each eye. ${ }^{7}$ Dominant optic atrophy causes very gradually progressive or nonprogressive visual loss.

In general, optic nerve disease produces negative and retinal disease positive visual phenomena, but photopsiae do occur in optic neuropathy. Micropsia, macropsia, and central visual distortion strongly suggest macular dysfunction. Night blindness indicates rod dysfunction, although many patients with optic nerve dysfunction complain of particularly poor vision in dim light. Deterioration of vision with increased body temperature either from external heating or induced by exercise (Uhthoff's phenomenon) most commonly occurs in demyelinating optic neuropathy, especially in primary progressive multiple sclerosis, but it may occur with many types of optic neuropathy. Gaze-evoked amaurosis characteristically occurs with optic nerve sheath meningioma but may be produced by other lesions deforming the optic nerve, including primarily extraorbital disease. ${ }^{8}$

Ischaemic optic neuropathy in a patient aged over 50 years necessitates exclusion of giant cell arteritis., 10 Jaw claudication is almost pathognomonic. Recent onset severe headache, scalp tenderness, polymyalgia rheumatica, and general malaise are important features. Confusion and angina are serious features indicating cerebral and coronary insufficiency. It also needs to be borne in mind that nonarteritic anterior ischaemic optic neuropathy rarely occurs in optic discs with large cups. $^{11,12}$

\section{Signs}

Although the intraocular portion of the optic nerve is accessible to clinical examination, except for congenital optic disc anomalies, optic disc abnormalities are generally not specific to one or other aetiology. There are, however, patterns of physical signs that are characteristic of certain optic nerve disorders, but this necessitates routine assessment of several parameters, particularly central vision, colour vision, visual fields, and pupillary responses as well as optic disc abnormalities. ${ }^{1}$ These parameters also provide ways of monitoring and screening for optic nerve dysfunction.

Central vision is most commonly assessed by measurement of the threshold of spatial resolution (visual acuity) using identification of high contrast letters (eg Snellen charts or Bailey-Lovie, EDTRS, or New York Lighthouse logMAR charts). Contrast sensitivity charts, using either letters (Pelli-Robson and low-contrast Bailey-Lovie charts) or sinusoidal gratings (Vistech chart), provide more comprehensive assessment of spatial resolution. ${ }^{13}$ They generally add little extra information in clinical practice but are valuable for research. Visual acuity is best assessed with accurate refractive correction, but a pinhole is widely used to overcome refractive error. Both distance and near acuities should be measured as greater reduction in near than distance visual acuity is suggestive of macular dysfunction. The photostress test, which determines recovery of visual acuity after exposure to a bright light, is recommended for detecting macular dysfunction but is not often used in clinical practice.

Colour vision is commonly regarded as a specific test for optic nerve dysfunction, but it is also reduced in macular disease. However, acquired colour vision deficit in the presence of relatively good visual acuity is strongly suggestive of optic nerve dysfunction. In clinical practice in the UK, the Ishihara pseudoisochromatic colour plates, originally designed to detect inherited red-green colour vision defects with little ability to test for blue-yellow dyschromatopsia, are most commonly used because of their speed and simplicity. More systematic testing with the Farnsworth Panel D-15, the Lanthony 15-Hue Desaturated Test, or even the Farnsworth-Munsell 100 Hues test is usually reserved for research studies. Kollner's rule states that red/green dyschromatopsia indicates optic nerve or posterior visual pathway disease and blue/yellow or blue dyschromatopsia indicates retinal disease, but there are a number of conditions that contradict it particularly glaucoma, autosomal dominant 
optic atrophy, chronic papilloedema, and even acute demyelinating optic neuropathy. ${ }^{14,15}$

Visual fields testing is crucial for the diagnosis and monitoring of optic neuropathies. Certain visual field defects are associated with, but not specific to, various optic neuropathies (Table 2) and important research has been derived from such clinical observations. ${ }^{16-21}$ Identification of visual field defects indicative of optic nerve disease is historically based upon kinetic perimetry, particularly Goldmann and tangent screen perimetry. The Optic Neuritis Treatment Trial highlighted the seemingly different results obtained with computerised static perimetry, although this may simply reflect differences in interpretation. ${ }^{22}$ Diffuse loss on Humphrey 30-2 is probably equivalent to a central scotoma on Goldmann perimetry. Similarly, on computerised perimetry eccentric fixation may influence the pattern of visual field defect. It is necessary for clinicians to gain experience for each visual field testing technique, as well as bearing in mind that visual field defects are not pathognomonic.

For monitoring optic neuropathy, computerised perimetry is the best available technique, providing sensitivity, reproducibility, and concentrating on the central visual field. It also provides correlation to retinal ganglion cell loss. ${ }^{23,24}$

The optimal technique for visual field assessment changes according to circumstances, varying with the abilities and experience of the subject and the examiner (Table 3). Goldmann perimetry, increasingly abandoned by many ophthalmic departments, has particular value for determining the pattern of visual field loss, which is so important for localisation of disease within the visual pathways, and for examination of the aged, infirm, or individuals with severe visual loss.

Other visual field techniques include short wavelength (blue on yellow) automated perimetry (SWAP),${ }^{25-28}$ highpass resolution (ring) perimetry (HRP) aimed at testing the parvocellular pathway, ${ }^{29,30}$ flicker (Medmont automated) perimetry, ${ }^{31}$ motion perimetry, ${ }^{26}$ and frequency doubling perimetry (FDP) aimed at testing the magnocellular pathway, and rarebit (microdot) perimetry. ${ }^{32,33}$ Frequency doubling perimetry is widely used by optometrists, primarily screening for glaucoma. It has been shown to be poor at detecting postchiasmal lesions. ${ }^{31,34-39}$

Pupillary responses and optic disc abnormalities are the principal objective signs in the assessment of optic nerve disease. The relative afferent pupillary defect is a crucial sign in excluding nonorganic visual loss and a helpful sign to neurologists of previous optic neuropathy in patients thought to have demyelinating disease. ${ }^{40}$ Clinical assessment is subject to observer experience and bias, and pupil perimetry suffers from variations in the subject's level of arousal. However, there is reasonable correlation between the magnitude of the relative

Table 2 Visual field defects in optic nerve disorders

1. Focal

(a) Central scotoma

(i) Demyelinating optic neuropathy (centred on fixation with sloping border on Goldmann perimetry, ${ }^{69}$ diffuse/global loss on Humphrey $30-2^{22,70}$ )

(ii) Toxic/nutritional optic neuropathy ${ }^{71}$ (small, best detected with red target)

(iii) Leber's hereditary optic neuropathy (large, dense, steep-sided ${ }^{6}$ )

(iv) Compressive optic neuropathy ${ }^{72,73}$

(b) Enlarged blind spot

(i) Papilloedema

(ii) Congenital optic disc anomalies

(c) Respecting horizontal meridian - altitudinal, arcuate, nasal step, or inferonasal constriction

(i) Anterior ischaemic optic neuropathy (inferior altitudinal) $)^{69,74}$

(ii) Papilloedema

(iii) Glaucoma

(iv) Optic nerve head drusen

(d) Upper temporal field loss not respecting vertical meridian

(i) Tilted optic discs

(e) Nasal field loss respecting vertical meridian

(i) Intracranial optic nerve compression ${ }^{75}$

(ii) Primary empty sella syndrome ${ }^{76}$

(f) Junctional scotoma of Traquair (unilateral temporal paracentral hemianopic scotoma) - prechiasmatic optic nerve ${ }^{77}$

(g) 'Junctional scotoma' (central scotoma with contralateral superotemporal depression) - prechiasmatic optic nerve ${ }^{78}$

2. Diffuse

(a) Generalised depression

(b) Generalised constriction 
Table 3 Features of commonly used visual field testing techniques

\begin{tabular}{|c|c|c|}
\hline Technique & Methodology & Characteristics \\
\hline \multirow[t]{4}{*}{ Confrontation } & Kinetic or static (red desaturation) & Most easily and readily performed \\
\hline & Full field & Best performed with small $(5 \mathrm{~mm})$ red target ${ }^{79}$ \\
\hline & Suprathreshold & Interexaminer variability \\
\hline & Semiquantitative & \\
\hline \multirow[t]{4}{*}{ Amsler grid } & Static & Easy to perform \\
\hline & Central $10^{\circ}$ & Portable \\
\hline & Suprathreshold & Limited visual field \\
\hline & Semiquantitative & \\
\hline \multirow{5}{*}{ Tangent screen } & Kinetic or static & Easy to perform \\
\hline & Central $30^{\circ}$ & Detection of subtle central scotomas and non organic visual loss \\
\hline & Suprathreshold & Interexaminer variability \\
\hline & Coloured targets & \\
\hline & Semiquantitative & \\
\hline \multirow{6}{*}{$\begin{array}{l}\text { Goldmann } \\
\text { perimetry }\end{array}$} & Kinetic or static & Requires experienced examiner \\
\hline & Full field & Best for determining pattern of field defect \\
\hline & Suprathreshold or threshold & Examination of aged, infirm or individuals with severe visual loss \\
\hline & $\begin{array}{l}\text { Wide range of stimulus size } \\
\text { (I-V) and intensities }\end{array}$ & Detection of non-organic visual loss \\
\hline & $\begin{array}{l}(1-4, \text { a-e }) \text { - standard targets: } \\
\text { I2e, } I 4 \mathrm{e}, \mathrm{V} 4 \mathrm{e}^{80}\end{array}$ & \\
\hline & Quantitative & Inter-examiner variability \\
\hline \multirow{7}{*}{$\begin{array}{l}\text { Computerised } \\
\text { perimetry }\end{array}$} & Static (or kinetic) & Difficult to perform \\
\hline & Central $\left(30^{\circ}, 24^{\circ}\right.$ or $\left.10^{\circ}\right)$ or full field & Most sensitive and reproducible \\
\hline & Threshold (full threshold/SITA - & Fixation monitoring - blind spot, gaze-tracking \\
\hline & $\begin{array}{l}\text { central } 30-2,24-2,10-2) \text { or } \\
\text { suprathreshold (screening - } \\
\text { central } 76 \text { point, full-field } 120 \text { point, } \\
\text { Esterman) } \\
\text { Standard target size (III) - others } \\
\text { available }^{81}\end{array}$ & Reliability indices - fixation losses, false positives, false negatives \\
\hline & $\begin{array}{l}\text { Coloured stimuli } \\
\text { Quantitative }\end{array}$ & $\begin{array}{l}\text { Absolute retinal thresholds (numerical and gray scale) including foveal } \\
\text { sensitivity }\end{array}$ \\
\hline & & $\begin{array}{l}\text { Comparison with age-matched controls - total and pattern deviation } \\
\text { (numerical and probability) }\end{array}$ \\
\hline & & $\begin{array}{l}\text { Overall performance indices - mean deviation, pattern standard deviation, } \\
\text { corrected pattern standard deviation, glaucoma hemifield test }\end{array}$ \\
\hline
\end{tabular}

afferent pupillary defect and visual field loss, and hence estimated retinal ganglion cell loss, ${ }^{41-46}$ but with differences in the slope of the regression line between types of optic neuropathy, suggesting a differential effect on retinal ganglion cells subserving luminance and pupil responses. ${ }^{43,46-53}$

Abnormalities of the optic disc include congenital anomalies, swelling or elevation (see below), pallor, and cupping. Congenital anomalies are usually identifiable on clinical examination, but their presence should not exclude consideration of acquired disease, particularly when there is subjective or objective evidence of deteriorating visual function.

Detection of papilloedema, optic disc swelling due to raised intracranial pressure, has serious implications because of the possibility of life-threatening intracranial disease. It is thus crucial to decide whether optic disc swelling is indeed due to raised intracranial pressure. Use of the term papilloedema for optic disc swelling of any aetiology confuses this process. Conversely, the term elevation rather than swelling of the optic nerve head can be useful to highlight the need to consider other entities (Table 4). The crowded nerve fibres of small optic discs, which are frequently associated with hypermetropia and may harbour buried drusen, may be a source of great confusion and are a frequent cause of referral from optometrists concerned about raised intracranial pressure.

The pattern of optic disc elevation rarely gives an absolute indication as to the underlying cause. ${ }^{54}$ The pattern of visual loss, associated symptoms such as pain on eye movements or transient visual obscurations, and other physical signs such as intraocular inflammation or retinal abnormalities must be taken into account. An 
Table 4 Causes of optic disc elevation

\begin{tabular}{l}
\hline Papilloedema (raised intracranial pressure) \\
\hline Anterior optic neuropathy \\
Ischaemic \\
Inflammatory \\
Infiltrative \\
Compressive (intra-orbital) \\
Pseudopapilloedema \\
Optic nerve head drusen (buried or exposed) \\
Small optic disc \\
Tilted optic disc \\
Myelinated nerve fibres \\
Pseudooedema \\
Leber's hereditary optic neuropathy \\
Methanol poisoning \\
Intraocular disease \\
Central retinal vein occlusion \\
Posterior uveitis \\
Posterior scleritis \\
Hypotony \\
Accelerated systemic hypertension
\end{tabular}

exception is exposed optic nerve head drusen, in which the craggy elevation of the optic disc surface, the refractile bodies on ophthalmoscopy, the small optic discs, the associated vascular anomalies, and possibly the detection of autofluorescence on slit-lamp examination, are characteristic, with confirmation when necessary provided by ultrasound examination. Retinochoroidal collaterals in association with optic disc pallor and progressive visual loss are characteristic of optic nerve sheath meningioma, and also they are a feature of chronic papilloedema and a sequel to central retinal vein occlusion.

The 'textbook' features of papilloedema-blurred disc margins and spontaneous venous pulsation - are not reliable. The optic disc margins are often indistinct in small or tilted optic discs. Spontaneous venous pulsation is not always present when the intracranial pressure is normal and has been shown to be present when the intracranial pressure is markedly elevated. When it does reliably reflect the intracranial pressure, its presence only indicates that the intracranial pressure is normal at the time of examination, whereas it is known that intracranial pressure fluctuates, particularly when elevated in conditions such as idiopathic intracranial hypertension. Whether the intracranial pressure is pathologically elevated is more reliably determined by other features, such as haemorrhages or cotton-wool spots on or around the optic disc, capillary dilatation on the disc surface, nerve fibre layer thickening with obscuration of the larger vessels on and around the disc, peripapillary retinal (Paton's) folds, choroidal folds, 'vintage' spots, comparison with the fellow eye, and changing appearance of the disc. Fluorescein angiography may also be helpful.

Optic disc cupping is characteristic but not pathognomonic of glaucoma, occurring also in anterior ischaemic optic neuropathy, ${ }^{55-61}$ especially when due to giant cell arteritis, optic nerve compression, ${ }^{62-65}$ autosomal dominant optic atrophy, ${ }^{66}$ and Leber's hereditary optic neuropathy. ${ }^{67}$ As demonstrated by studies of normal tension glaucoma, determining whether other causes of optic disc cupping should be considered depends upon the correlation between cupping and pallor of the disc, the pattern of visual loss, particularly whether the visual field defect corresponds to the pattern of cupping or respects the vertical rather than the horizontal meridian, changes in visual acuity and colour vision, and the age of the patient. ${ }^{68}$

Optic disc pallor is usually a sign of optic nerve disease, but it also occurs secondary to retinal disease, such as central retinal artery occlusion, or retinitis pigmentosa. Cone dystrophies classically may present with poor central and colour vision and pale optic discs with little macular abnormality, thus masquerading as bilateral optic neuropathy. Hence careful fundal examination is necessary. Detection of macular abnormalities is facilitated by use of a fundal contact lens rather than relying upon handheld slit-lamp biomicroscopy lenses or an ophthalmoscope. Visual electrophysiology or fluorescein angiography may, however, be required to establish the correct diagnosis.

If examination is normal, especially no relative afferent pupillary defect and no fundal abnormality to account for purported visual loss, consideration must be given to the possibility of nonorganic disease. Demonstration of inappropriate responses on testing visual acuity, visual fields, or colour vision then becomes crucial to avoid unnecessary investigation.

The parameters chosen for monitoring or screening for optic nerve disease should be those most sensitive to change for the particular disease entity. A reduction in visual acuity is a late manifestation of glaucoma and papilloedema, which are better monitored by visual field testing and optic disc examination. Loss of colour vision and optic disc pallor are commonly found in asymptomatic patients with dominant optic atrophy. Optic disc pallor may not be present in optic nerve compression, whereas a relative afferent pupillary defect and loss of colour vision are early features.

\section{Conclusion}

Optic nerve disorders provide a fascinating insight into a wide range of pathological processes. Clinical assessment provides a strong basis of information to both clinicians and research scientists. 


\section{References}

1 Rizzo III JF, Lessell S. Optic neuritis and ischemic optic neuropathy. Overlapping clinical profiles. Arch Ophthalmol 1991; 109: 1668-1672.

2 Levin LA, Rizzo III JF, Lessell S. Neural network differentiation of optic neuritis and anterior ischaemic optic neuropathy. Br J Ophthalmol 1996; 80: 835-839.

3 Van Stavern GP, Newman NJ. Optic neuropathies. An overview. Ophthalmol Clin North Am 2001; 14: 61-71.

4 Swartz NG, Beck RW, Savino PJ, Sergott RC, Bosley TM, Lam BL et al. Pain in anterior ischemic optic neuropathy. J Neuroophthalmol 1995; 15: 9-10.

5 Optic Neuritis Study Group. The clinical profile of optic neuritis. Experience of the Optic Neuritis Treatment Trial. Arch Ophthalmol 1991; 109: 1673-1678.

6 Lee AG, Lin DJ, Kaufman M, Golnik KC, Vaphiades MS, Eggenberger E. Atypical features prompting neuroimaging in acute optic neuropathy in adults. Can J Ophthalmol 2000; 35: 325-330.

7 Riordan-Eva P, Sanders MD, Govan GG, Sweeney MG, Da Costa J, Harding AE. The clinical features of Leber's hereditary optic neuropathy defined by the presence of a pathogenic mitochondrial DNA mutation. Brain 1995; 118: 319-337.

8 Otto CS, Coppit GL, Mazzoli RA, Eusterman VD, Nixon KL, Ainbinder DJ et al. Gaze-evoked amaurosis: a report of five cases. Ophthalmology 2003; 110: 322-326.

9 Boghen DR, Glaser JS. Ischaemic optic neuropathy. The clinical profile and history. Brain 1975; 98: 689-708.

10 Hayreh SS. Anterior ischaemic optic neuropathy. Differentiation of arteritic from non-arteritic type and its management. Eye 1990; 4: 25-41.

11 Beck RW, Savino PJ, Repka MX, Schatz NJ, Sergott RC. Optic disc structure in anterior ischemic optic neuropathy. Ophthalmology 1984; 91: 1334-1337.

12 Beck RW, Servais GE, Hayreh SS. Anterior ischemic optic neuropathy. IX. Cup-to-disc ratio and its role in pathogenesis. Ophthalmology 1987; 94: 1503-1508.

13 Trobe JD, Beck RW, Moke PS, Cleary PA. Contrast sensitivity and other vision tests in the optic neuritis treatment trial. Am J Ophthalmol 1996; 121: 547-553.

14 Katz B. The dyschromatopsia of optic neuritis: a descriptive analysis of data from the optic neuritis treatment trial. Trans Am Ophthalmol Soc 1995; 93: 685-708.

15 Schneck ME, Haegerstrom-Portnoy G. Color vision defect type and spatial vision in the optic neuritis treatment trial. Invest Ophthalmol Vis Sci 1997; 38: 2278-2289.

16 Olver JM, Spalton DJ, McCartney AC. Microvascular study of the retrolaminar optic nerve in man: the possible significance in anterior ischaemic optic neuropathy. Eye 1990; 4: 7-24.

17 Olver JM, Spalton DJ, McCartney AC. Quantitative morphology of human retrolaminar optic nerve vasculature. Invest Ophthalmol Vis Sci 1994; 35: 3858-3866.

18 Park KH, Tomita G, Onda E, Kitazawa Y, Cioffi GA. In vivo detection of perineural circular arterial anastomosis (circle of Zinn-Haller) in a patient with large peripapillary chorioretinal atrophy. Am J Ophthalmol 1996; 122 905-907.

19 Ohno-Matsui K, Futagami S, Yamashita S, Tokoro T. Zinn-Haller arterial ring observed by ICG angiography in high myopia. Br J Ophthalmol 1998; 82: 1357-1362.
20 Ko MK, Kim DS, Ahn YK. Morphological variations of the peripapillary circle of Zinn-Haller by flat section. $\mathrm{Br} J$ Ophthalmol 1999; 83: 862-866.

21 Gauntt CD, Williamson TH, Sanders MD. Relationship of the distal optic nerve sheath to the circle of Zinn. Graefes Arch Clin Exp Ophthalmol 1999; 237: 642-647.

22 Keltner JL, Johnson CA, Spurr JO, Beck RW. Baseline visual field profile of optic neuritis. The experience of the optic neuritis treatment trial. Optic Neuritis Study Group. Arch Ophthalmol 1993; 111: 231-234.

23 Kerrigan-Baumrind LA, Kerrigan DF, Miller NR, Quigley HA. Quantification of optic nerve axon loss associated with a relative afferent pupillary defect in the monkey. Arch Ophthalmol 2001; 119: 1333-1341.

24 Garway-Heath DF, Caprioli J, Fitzke FW, Hitchings RA. Scaling the hill of vision: the physiological relationship between light sensitivity and ganglion cell numbers. Invest Ophthalmol Vis Sci 2000; 41: 1774-1782.

25 Keltner JL, Johnson CA. Short-wavelength automated perimetry in neuro-ophthalmologic disorders. Arch Ophthalmol 1995; 113: 475-481.

26 Sample PA, Bosworth CF, Weinreb RN. Short-wavelength automated perimetry and motion automated perimetry in patients with glaucoma. Arch Ophthalmol 1997; 115: 11291133.

27 Racette L, Sample PA. Short-wavelength automated perimetry. Ophthalmol Clin North Am 2003; 16: 227-236.

28 Mojon DS, Zulauf M. Normal values of short-wavelength automated perimetry. Ophthalmologica 2003; 217: 260-264.

29 Frisén L. High pass resolution perimetry: Recent developments. In: Heijl A (ed), Perimetry Update 1988/1989. Kugler and Ghedini: Amsterdam, 1989 pp 383-392.

30 Chauhan BC, House PH, McCormick TA, LeBlanc RP. Comparison of conventional and high-pass resolution perimetry in a prospective study of patients with glaucoma and healthy controls. Arch Ophthalmol 1999; 117: 24-33.

31 Landers J, Sharma A, Goldberg I, Graham S. A comparison of perimetric results with the Medmont and Humphrey perimeters. Br J Ophthalmol 2003; 87: 690-694.

32 Frisen L. New, sensitive window on abnormal spatial vision: rarebit probing. Vision Res 2002; 42: 1931-1939.

33 Frisen L. Spatial vision in visually asymptomatic subjects at high risk for multiple sclerosis. J Neurol Neurosurg Psychiatry 2003; 74: 1145-1147.

34 Johnson CA, Cioffi GA, Van Buskirk EM. Frequency doubling technology perimetry using a 24-2 stimulus presentation pattern. Optom Vis Sci 1999; 76: 571-581.

35 Thomas D, Thomas R, Muliyil JP, George R. Role of frequency doubling perimetry in detecting neuroophthalmic visual field defects. Am J Ophthalmol 2001; 131: 734-741.

36 Wall M, Neahring RK, Woodward KR. Sensitivity and specificity of frequency doubling perimetry in neuroophthalmic disorders: a comparison with conventional automated perimetry. Invest Ophthalmol Vis Sci 2002; 43: 1277-1283.

37 Spry PG, Johnson CA. Within-test variability of frequencydoubling perimetry using a 24-2 test pattern. J Glaucoma 2002; 11: 315-320.

38 Fong KC, Byles DB, Constable PH. Does frequency doubling technology perimetry reliably detect neurological visual field defects? Eye 2003; 17: 330-333.

39 Anderson AJ, Johnson CA. Frequency-doubling technology perimetry. Ophthalmol Clin North Am 2003; 16: 213-225. 
40 Ellis CJ. The afferent pupillary defect in acute optic neuritis. J Neurol Neurosurg Psychiatry 1979; 42: 1008-1017.

41 Thompson HS, Montague P, Cox TA, Corbett JJ. The relationship between visual acuity, pupillary defect and visual field loss. Am J Ophthalmol 1982; 93: 681-688.

42 Johnson LN, Hill RA, Bartholomew MJ. Correlation of afferent pupillary defect with visual field loss on automated perimetry. Ophthalmology 1988; 95: 1649-1655.

43 Kardon RH, Haupert CL, Thompson HS. The relationship between static perimetry and the relative afferent pupillary defect. Am J Ophthalmol 1993; 115: 351-356.

44 Wilhelm H, Meilinger S, Apfelstedt E. [Relation between relative afferent pupillary defect and suprathreshold automated perimetry]. Klin Monatsbl Augenheilkd 1997; 210: 365-369 (in German).

45 Lagreze WD, Kardon RH. Correlation of relative afferent pupillary defect and estimated retinal ganglion cell loss. Graefes Arch Clin Exp Ophthalmol 1998; 236: 401-404.

46 Bobak SP, Goodwin JA, Guevara RA, Arya A, Grover S. Predictors of visual acuity and the relative afferent pupillary defect in optic neuropathy. Doc Ophthalmol 1999; 97: 81-95.

47 Wakakura M, Yokoe J. Evidence for preserved direct pupillary light response in Leber's hereditary optic neuropathy. Br J Ophthalmol 1995; 79: 442-446.

48 Jacobson DM, Stone EM, Miller NR, Pollock SC, Fletcher WA, McNussen PJ et al. Relative afferent pupillary defects in patients with Leber hereditary optic neuropathy and unilateral visual loss. Am J Ophthalmol 1998; 126: 291-295.

49 Ludtke H, Kriegbaum C, Leo-Kottler B, Wilhelm H. Pupillary light reflexes in patients with Leber's hereditary optic neuropathy. Graefes Arch Clin Exp Ophthalmol 1999; 237: 207-211.

50 Yoshitomi T, Matsui T, Tanakadate A, Ishikawa S. Comparison of threshold visual perimetry and objective pupil perimetry in clinical patients. J Neuroophthalmol 1999; 19: 89-99.

51 Bremner FD, Shallo-Hoffmann J, Riordan-Eva P, Smith SE. Comparing pupil function with visual function in patients with Leber's hereditary optic neuropathy. Invest Ophthalmol Vis Sci 1999; 40: 2528-2534.

52 Sadun AA, Win PH, Ross-Cisneros FN, Walker SO, Carelli V. Leber's hereditary optic neuropathy differentially affects smaller axons in the optic nerve. Trans Am Ophthalmol Soc 2000; 98: 223-232.

53 Bremner FD, Tomlin EA, Shallo-Hoffmann J, Votruba M, Smith SE. The pupil in dominant optic atrophy. Invest Ophthalmol Vis Sci 2001; 42: 675-678.

54 Warner JE, Lessell S, Rizzo III JF, Newman NJ. Does optic disc appearance distinguish ischemic optic neuropathy from optic neuritis? Arch Ophthalmol 1997; 115: $1408-1410$.

55 Quigley H, Anderson DR. Cupping of the optic disc in ischemic optic neuropathy. Trans Am Acad Ophthalmol Otolaryngol 1977; 83: 755-762.

56 Trobe JD, Glaser JS, Cassady J, Herschler J, Anderson DR. Nonglaucomatous excavation of the optic disc. Arch Ophthalmol 1980; 98: 1046-1050.

57 Sebag J, Thomas JV, Epstein DL, Grant WM. Optic disc cupping in arteritic anterior ischemic optic neuropathy resembles glaucomatous cupping. Ophthalmology 1986; 93 : 357-361.
58 Jonas JB, Xu L. Optic disc morphology in eyes after nonarteritic anterior ischemic optic neuropathy. Invest Ophthalmol Vis Sci 1993; 34: 2260-2265.

59 Jonas JB, Bergua A, Schmitz-Valckenberg P, Papastathopoulos KI, Budde WM. Ranking of optic disc variables for detection of glaucomatous optic nerve damage. Invest Ophthalmol Vis Sci 2000; 41: 1764-1773.

60 Danesh-Meyer HV, Savino PJ, Sergott RC. The prevalence of cupping in end-stage arteritic and nonarteritic anterior ischemic optic neuropathy. Ophthalmology 2001; 108: 593-598.

61 Hayreh SS, Jonas JB. Optic disc morphology after arteritic anterior ischemic optic neuropathy. Ophthalmology 2001; 108: 1586-1594.

62 Portney GL, Roth AM. Optic cupping caused by an intracranial aneurysm. Am J Ophthalmol 1977; 84: 98-103.

63 Kupersmith MJ, Krohn D. Cupping of the optic disc with compressive lesions of the anterior visual pathway. Ann Ophthalmol 1984; 16: 948-953.

64 Kalenak JW, Kosmorsky GS, Hassenbusch SJ. Compression of the intracranial optic nerve mimicking unilateral normal-pressure glaucoma. J Clin Neuroophthalmol 1992; 12: 230-235.

65 Bianchi-Marzoli S, Rizzo III JF, Brancato R, Lessell S. Quantitative analysis of optic disc cupping in compressive optic neuropathy. Ophthalmology 1995; 102: 436-440.

66 Fournier AV, Damji KF, Epstein DL, Pollock SC. Disc excavation in dominant optic atrophy: differentiation from normal tension glaucoma. Ophthalmology 2001; 108: 1595-1602.

67 Mashima Y, Kimura I, Yamamoto Y, Ohde H, Ohtake Y, Tanino T et al. Optic disc excavation in the atrophic stage of Leber's hereditary optic neuropathy: comparison with normal tension glaucoma. Graefes Arch Clin Exp Ophthalmol 2003; 241: 75-80.

68 Greenfield DS, Siatkowski RM, Glaser JS, Schatz NJ, Parrish II RK. The cupped disc. Who needs neuroimaging? Ophthalmology 1998; 105: 1866-1874.

69 Gerling J, Meyer JH, Kommerell G. Visual field defects in optic neuritis and anterior ischemic optic neuropathy: distinctive features. Graefes Arch Clin Exp Ophthalmol 1998; 236: 188-192.

70 Fang JP, Donahue SP, Lin RH. Global visual field involvement in acute unilateral optic neuritis. Am J Ophthalmol 1999; 128: 554-565.

71 Sadun AA, Martone JF, Muci-Mendoza R, Reyes L, DuBois L, Silva JC et al. Epidemic optic neuropathy in Cuba. Eye findings. Arch Ophthalmol 1994; 112: 691-699.

72 Gutman I, Behrens M, Odel J. Bilateral central and centrocaecal scotomata due to mass lesions. $\mathrm{Br} J$ Ophthalmol 1984; 68: 336-342.

73 Page NG, Sanders MD. Bilateral central scotomata due to intracranial tumour. Br J Ophthalmol 1984; 68: 449-457.

74 Reuscher A, Chromek W, Kommerell G. [Visual field defects and fluorescein angiography in acute anterior ischemic optic neuropathy (author's transl)]. Klin Monatsbl Augenheilkd 1978; 173: 69-74 (in German).

75 Manor RS, Ouaknine GE, Matz S, Shalit MN. Nasal visual field loss with intracranial lesions of the optic nerve pathways. Am J Ophthalmol 1980; 90: 1-10. 
76 Charteris DG, Cullen JF. Binasal field defects in primary empty sella syndrome. J Neuroophthalmol 1996; 16: 110-114.

77 Mojon DS, Odel JG, Rios RJ, Hirano M. Pituitary adenoma revealed by paracentral junctional scotoma of traquair. Ophthalmologica 1997; 211: 104-108.

78 Karanjia N, Jacobson DM. Compression of the prechiasmatic optic nerve produces a junctional scotoma. Am J Ophthalmol 1999; 128: 256-258.
79 Pandit RJ, Gales K, Griffiths PG. Effectiveness of testing visual fields by confrontation. Lancet 2001; 358: 1339-1340.

80 Trobe JD, Glaser JS. Quantitative perimetry in compressive optic neuropathy and optic neuritis. Arch Ophthalmol 1978; 96: 1210-1216.

81 Wall M, Kutzko KE, Chauhan BC. Variability in patients with glaucomatous visual field damage is reduced using size V stimuli. Invest Ophthalmol Vis Sci 1997; 38: 426-435. 